\title{
Construction of Large Dams and their Impact on Cultural Landscape: A Study in Victoria Reservoir and the Surrounding Area
}

\author{
C.J. Wijesundara and N.D.K. Dayawansa ${ }^{1 *}$ \\ Postgraduate Institute of Agriculture \\ University of Peradeniya \\ Sri Lanka
}

\begin{abstract}
Large dam projects are implemented aiming for multiple benefits including water for agriculture, power generation and flood control. There are considerable environmental and social changes behind these large dam projects, which have not been discussed openly compared to the benefits received from them. However, it is important to analyse the social and environmental changes that could occur as a result of these dam projects in order to evaluate the net benefits received. This study focused on studying the changes in the cultural landscape of Teldeniya and surrounding area due to the construction of the Victoria reservoir. To achieve this objective, a methodology was developed utilizing topographical maps and remotely sensed data. Various spatial and non spatial data belonging to two periods: 1954 represent pre and 2003 post construction periods of the reservoir. The topographical maps were georectified and specific area of interest was obtained. Data of 1954, 2003 obtained from topographic maps were analysed to assess the changes in the landscape. In addition, an IRS LISS III satellite imagery acquired in 1998 was also classified and analysed to support the study. Comparisons were made among the information extracted from 1954, 1998 and 2003 to assess the changes in the cultural landscape of the study area. The study revealed that the land use, road network and the hydrological network have changed considerably. There is a drastic change in the cultural landscape of the study area as a result of the construction of the Victoria reservoir. Some of the land used previously has been submerged with the construction of the dam. The dam project has brought new livelihood options to the people in the area. It is clear that these repercussions are partly due to the changes that have occurred with the development of technology and society with time. The significance of this is that drastic changes are not only on tangible physical changes but also intangible aspects such as culture and the society of this region.
\end{abstract}

Key words: Dams, Reservoirs, Spatial data, Victoria.

\section{INTRODUCTION}

History of large dams goes back to thousands of years. Supply of water for irrigation and domestic needs, hydropower generation and flood control are the primary objectives of constructing large dams. As a result, large dam projects have gained high popularity both in developed and developing countries. At present, nearly half of the world's rivers has at least one large dam to meet the water and energy needs of growing population (World Commission on Dams, 2001). However, from 1950s the negative impacts of these large

To whom correspondence should be addressed: dammid@pdn.ac.lk

Department of Agricultural Engineering, Faculty of Agriculture, University of Peradeniya, Sri Lanka 
development projects such as mass scale displacement of people, changes in river hydrology and ecology, impacts on plants and animals have started to emerge. These negative impacts have seldom been studied in detail in the process of formulating development proposals since more weight was given to the positive outcomes associated with these programmes. Sri Lanka has a great hydraulic civilization and the construction of dams and hydraulic structures is not new to the country. In the recent past, four large dams namely, Kotmale, Victoria, Randenigala and Rantembe were constructed under the Mahaweli development program. These dam projects have brought multiple benefits to the country including supply of irrigation water, hydropower generation, flood control, socio-economic development in the new irrigation systems, infrastructure development etc. However, there are some evidences to show the negative impacts of these large dams and reservoirs since hardly any few studies have been carried out on this issue.

This study mainly focuses on the changes in the cultural landscape of Teldeniya and the surrounding area as a result of the construction of Victoria dam. Victoria Dam is situated 300 m below the confluence of the Hulu Ganga and just above the Victoria rapids on Mahawali river. It is a double curvature arch dam with a height of $118 \mathrm{~m}$ and a length of $507 \mathrm{~m}$ along its crest. This reservoir became operational by the mid 1984 and inundated the lands upstream, lying below $438 \mathrm{~m}$ (1440 ft) contour (Mahaweli, 1986).

The 'Cultural Landscape' can be generally defined as a "geographical area including both cultural resources and natural resources". Cultural resources may contain all the man-made physical structures, and phenomena such as traditional/ religious/ aesthetic aspects, etc. According to Fowler (2003), cultural landscape represents the combined works of nature such as streams, mountains, forests and man-made aspects such as roads, settlements, cultivations etc. It illustrates the evolution of human society and settlements over time, under the influence of the physical constraints and/ or opportunities presented by their natural environment. Cultural landscape often reflects specific techniques of sustainable land use.

Cultural landscape can be changed with time due to natural and man made reasons. The process can be accelerated with high level of human influence such as large scale constructions like roads, bridges, dams, etc.

\section{Objective of the study}

The objective of this study is to identify the changes in the cultural landscape of Teldeniya and the surroundings as a result of the construction of Victoria reservoir.

\section{The Study area}

The area considered in the study is the Victoria reservoir and its surroundings. The elevation of the area ranges between 400-600 m and in places like Bambaragala it rises up to $681 \mathrm{~m}$. This is a hilly area with narrow valleys and this topography is clearly visible in contour maps of the region. Even the flow of the Mahaweli river and other minor streams show the uneven physical appearance of the area (Fig. 1). The average temperature of the region is $24^{\circ} \mathrm{C}$ and the annual rainfall is approximately $1700 \mathrm{~mm}$. The relative humidity varies from $72-95 \%$ annually (Somasekaram, 1997).

At present, the western part of the region is dominated by coconut cultivations. Paddy cultivations are confined to the northern and south-western parts. Most of the settlements are gathered in the northern and south-western sectors and therefore home gardens are spreads 
throughout these areas. The major transportation network too spread among the settlements in the northern and western parts of the region.

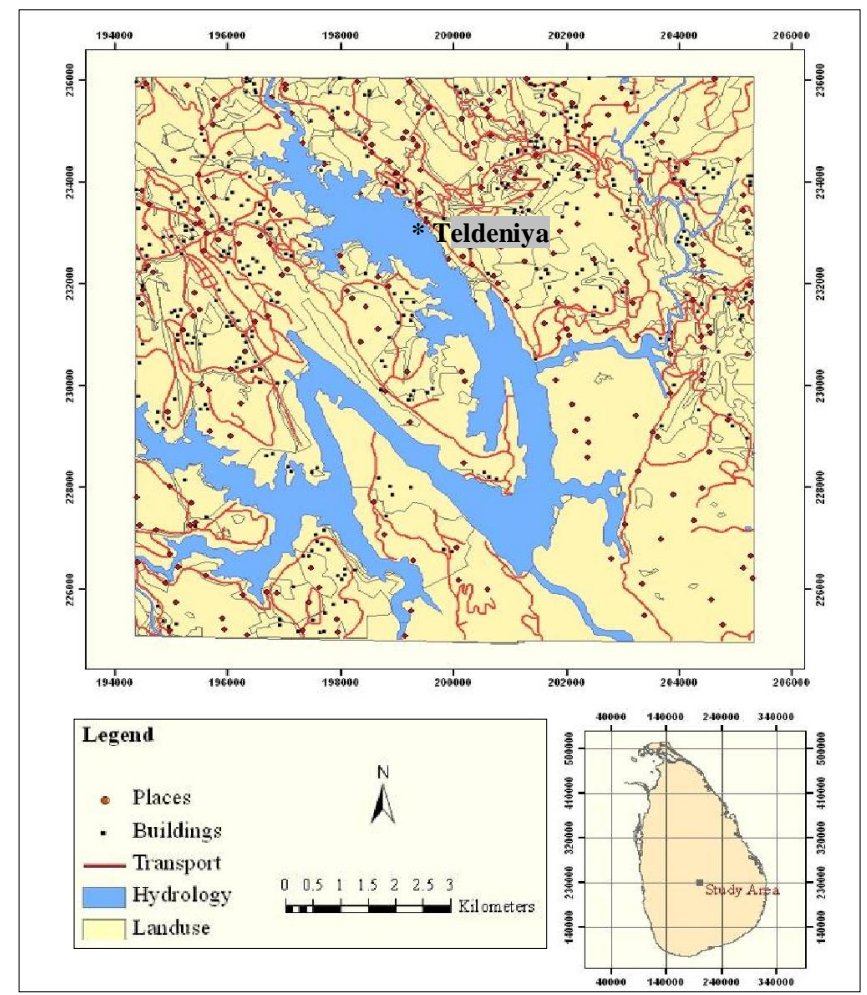

Fig.1. Location map showing the study area

(Source: Survey Department of Sri Lanka, 2003)

It is clearly visible that the target region is dominated by forests and scrub lands which is nearly $45 \%$ of the total area. This is due to the declaration of some of the areas within the Victoria Project as 'Protected Wildlife' sanctuaries. This part of the sanctuary belongs to Victoria, Randenigala and Rantambe sanctuary (Generally termed as VRR Sanctuary) which has been declared as a wildlife sanctuary in 1987 .

Five decades ago, the old Teldeniya and its suburbs was a typical traditional site with a number of small villages. With respect to the cultural landscape of the region in this time, it is clear that there were no reservoir or water body other than the Mahaweli river and its tributaries. According to the topographical map of Teldeniya and its suburbs in year 1954, eastern and the middle parts covering nearly $40 \%$ of the region can be recognized as barren lands which contain no cultivation or human settlements.

When identifying the study area, historical and archaeological values are very important because present human settlement conditions are a reflection of the earlier settlement patterns and culture. The 'Brahmi' inscriptions found at ancient temples such as Gonawatta and Bambaragala indicate that the area had human settlements since $1^{\text {st }}$ century B.C. Of the above two sites, Bambaragala is the most important archaeological site within the specified area. It can be approached from Teldeniya road and is about $19 \mathrm{~km}$ from Kandy. 


\section{MATERIALS AND METHODS}

Since this is a multi-temporal analysis which needs to assess conditions before and after construction of Victoria reservoir, two topographical maps were analysed for 1954 \& 2003. As additional data, satellite image acquired in 1998 by India Remote Sensing - Linear Imaging Self-Scanning Sensor III (IRS LISS III) was used as remotely sensed data. ERDAS Imaging $8.5 \&$ ArcGIS 9.3 software was used for remotely sensed data analysis and for GIS analysis.

Apart from the maps and images, written and digital materials such as books, journals, articles, etc. were used as references for this study. Field visits were conducted to have a correct overview of the study area.

\section{Methodology}

Basically, this consists of data collection, preparation and analysis. The majority of data used in the exercise were spatial data.

The maps were scanned and geo-referenced and the image was geometrically corrected. There was no specific boundary for the study area. It was decided based on the distribution of the reservoir in the landscape. Supervised and unsupervised classification techniques were applied to the satellite image to extract land use information. Two separate data sets were obtained for 1954 and 2003. They contained information of the region such as buildings, places, road network, land use etc. Multi temporal data layers were compared using GIS techniques to identify the changes that had occurred in the area.

Another separate data layer for land use in 1998 was generated based on the classified IRS LISS-III image as special information in this study.

Digital Elevation Model (DEM) was created during the data processing phase and the model was overlaid with the digital data layers of years 1954 and 2003. These models gave a three dimensional view of the area in different angles which provides different and clear analysis of the region.

Statistics of the changes were also calculated and tabulated.

\section{RESULTS AND DISCUSSION}

\section{Land use changes}

According to Table. 1 and Figures 2 (a), 2 (b), 3, and 5 which represent the total land use conditions in 1954, 1998 and 2003, it is clear that the major crops such as paddy and coconut have decreased to a considerable extent. In year 1954, total paddy cultivation was nearly 1361 ha and in 1998 it was 791 ha and in 2003 it has decreased to 597 ha. The coconut cultivations which occupied nearly 2531 ha in 1954 have been reduced to 337 ha in 2003 . However, the home gardens have increased from 1905 ha in 1954 to 5946 in 2003. This shows the increasing population pressure in the area. The reduction of paddy lands and coconut cultivations indicate that livelihoods of the people are shifting from agriculture. In addition to these major land uses, extents of others such as forests, scrubs, barren lands and uncultivated lands have also changed with time. 

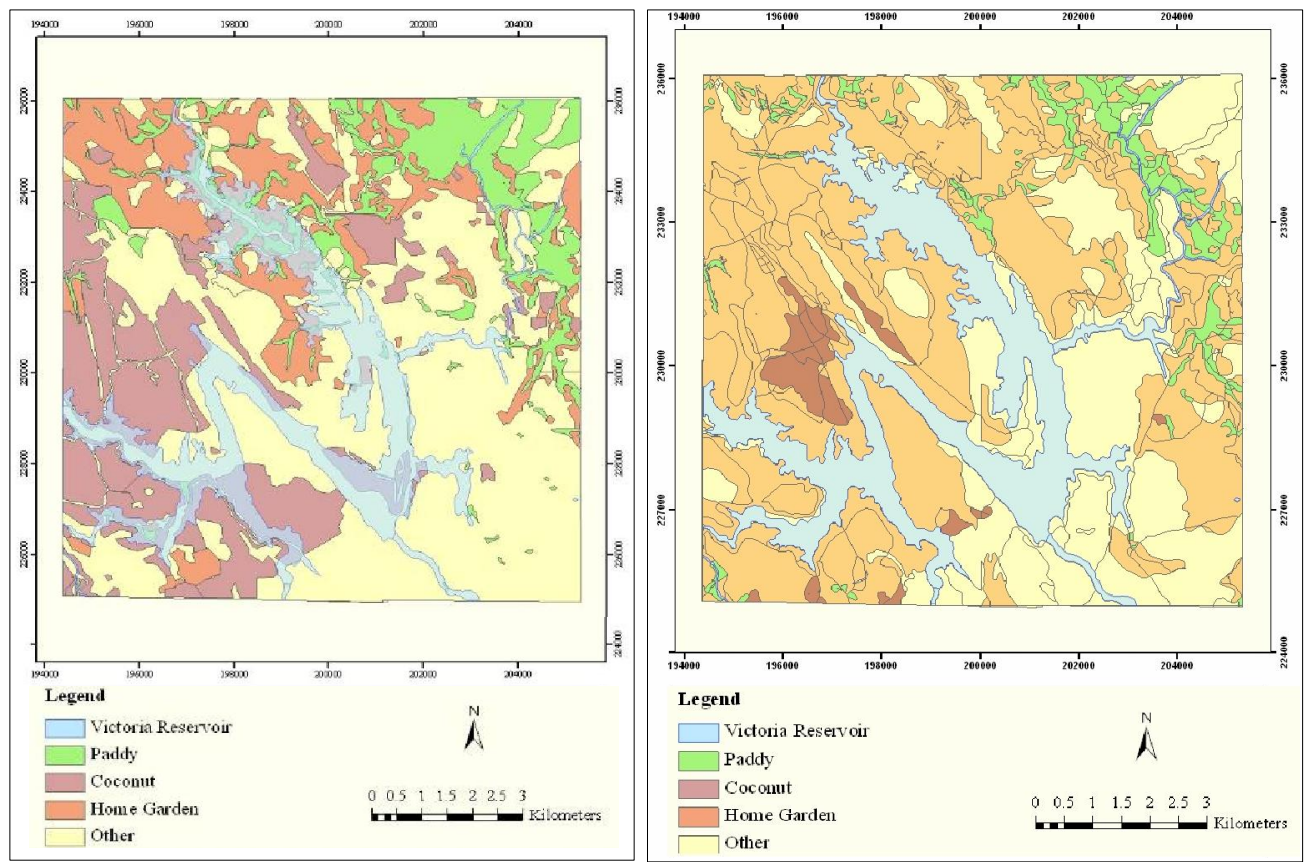

Fig. 2 (a). Land use map of the area in 1954 Fig. 2 (b). Land use map of the area in 2003

(Source: Survey Department of Sri Lanka, 1954 and 2003)

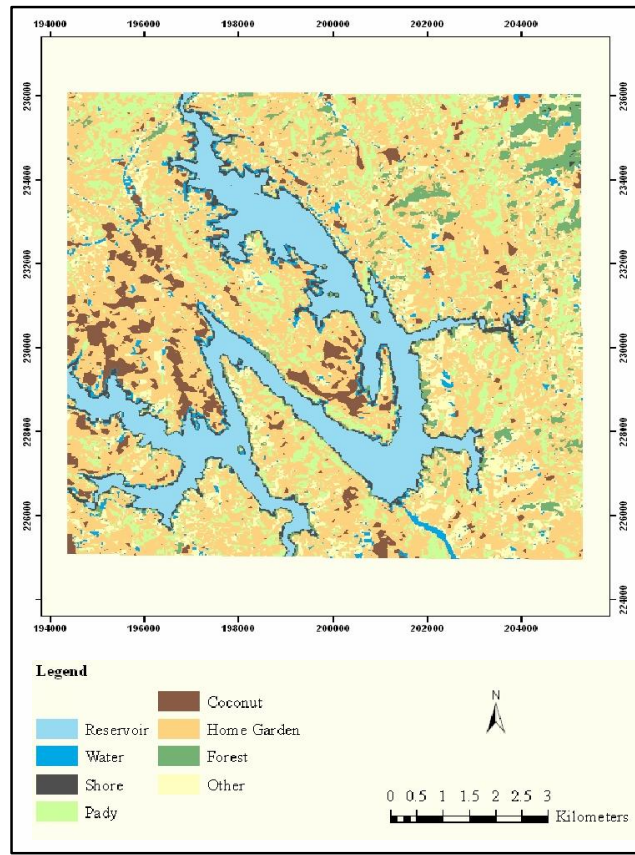

Fig. 3. Land use map of the area in 1998 (Source: IRS LISS III image, 1998)

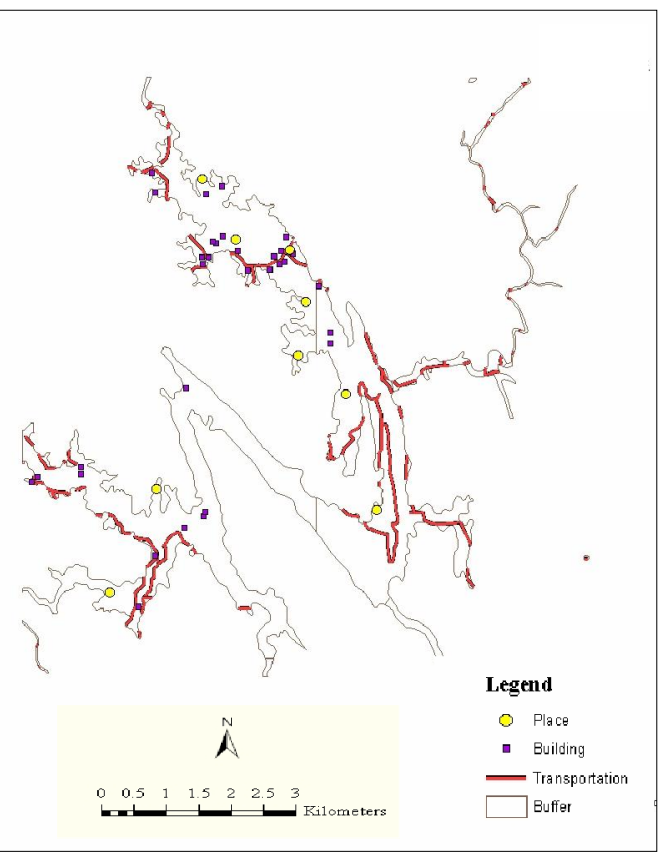

Fig. 4. Affected roads, buildings and places in the area (Based on 1954 data) 
Table 1. Land use of the study area in year 1954, 1998 and 2003

\begin{tabular}{lccc}
\hline Land use & $\mathbf{1 9 5 4}$ (ha) & $\mathbf{1 9 9 8}$ (ha) & $\mathbf{2 0 0 3}$ (ha) \\
\hline Paddy & 1361 & 792 & 597 \\
Coconut & 2532 & 373 & 338 \\
Home Garden & 1905 & 4686 & 5946 \\
Other Lands & 6230 & 6177 & 5147 \\
Total (ha) & 12028 & 12028 & 12028 \\
\hline
\end{tabular}

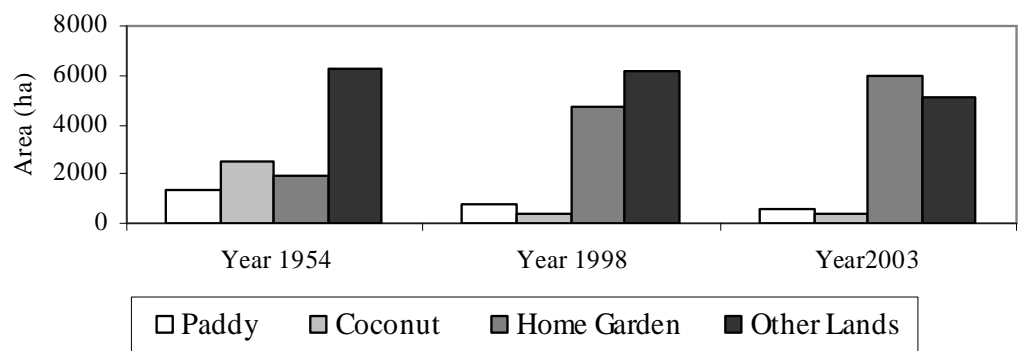

Fig. 5. Land use distribution in each year

Table. 2 shows the land uses that were affected by the reservoir. It is clear that all four land use types are significantly affected due to the reservoir.

Table 2. Land uses affected by the Victoria reservoir (based on 1954 and 2003 data)

\begin{tabular}{lccc}
\hline Land use & Total land use (ha) & Affected land use (ha) & \% of the total area \\
\hline Paddy & 1361 & 186 & 13.7 \\
Coconut & 2532 & 395 & 15.6 \\
Home Gardens & 1905 & 217 & 11.4 \\
Other Lands & 6230 & 1127 & 18.1 \\
Total (ha) & 12028 & 1925 & 16.0 \\
\hline
\end{tabular}

\section{Changes in Infrastructure}

Table. 3 and Fig. 4 present the road network and affected roads in the study area. In 1954, the total length of roads was approximately $154.7 \mathrm{~km}$. It includes approximately $33.7 \mathrm{~km}$ of major roads, $44.8 \mathrm{~km}$ of minor roads and $76.3 \mathrm{~km}$ of foot paths. The total inundated roads were about $28.6 \mathrm{~km}$. In 2003 road network has improved and the total length was over 459 $\mathrm{km}$. It includes $42.8 \mathrm{~km}$ major roads, $61.7 \mathrm{~km}$ minor and $354.6 \mathrm{~km}$ foot paths. This shows the general development of the area with time. 
Table. 3. Road network of the region in 1954 and 2003 and details of the inundated roads

\begin{tabular}{lccc}
\hline Type & Year 1954 & Year 2003 & Affected roads (based on 1954 data) \\
\hline Major Roads & 33.7 & 42.8 & 9.0 \\
Minor Roads & 44.8 & 61.7 & 10.8 \\
Paths & 76.2 & 354.6 & 8.8 \\
Total $(\mathrm{km})$ & 154.7 & 459.1 & 28.6 \\
\hline
\end{tabular}

According to the building distribution in the area (Fig. 4), some of the buildings have gone under water due to the reservoir. There are nine important places which have been inundated due to the reservoir including Teldeniya town. Other rural places such as Kudadeniya and Henagehuwela are not completely inundated. However, Teldeniya town has gone under water completely. Therefore, people had to be relocated in towns of Digana, Kundasala, Karalliyada and other places such as Udispattuwa, Udawela and Adikarigama.

Hydrological network is very important as it is the main reason for the changes in the cultural landscape of the region. The major change in terms of hydrological network during the study period from 1954 to 2003 is the reservoir. The whole Victoria reservoir and the major water ways were about 1924 ha in 2003.

\section{Social changes}

Social factors include people, their behavior, consumption patterns, beliefs and many other aspects. According to the statistical records from related reports, 6000 families $(30,000$ members) and 3098 houses have been affected due to reservoir construction directly or indirectly and 5546 families (23,209 members) have been totally affected by the reservoir. In terms of ethnicity, $85 \%$ Sinhalese people, $7.61 \%$ Tamils and $7.12 \%$ Muslims have been affected (Madduma Bandara, 1982).

Majority of the Sinhalese were the farming group of the region and there were 482 'Ande' tenants who cultivated others lands (Madduma Bandara, 1982). According to the land use analysis in this study that a considerable change had occurred in the paddy and coconut cultivations due to reservoir construction. With the inundation of cultivable lands to the reservoir, the farmers of these lands may have started their cultivations in the relocated lands or may have completely abandoned farming as their livelihood. Also, minority Tamils and Muslims have played the economic and business roles of the region. Most of the business activities of the region, especially in Teldeniya town have been carried out by those people. With the inundation of Teldeniya town and relocation of these people, there is a possibility in changing livelihoods.

Four percent of the lands affected by the reservoir are within the town limits and $96 \%$ is in the rural areas outside the town limits. Nearly $80 \%$ of the lands are private lands of the people also lived in the same area (Madduma Bandara, 1982). As discussed earlier major crops, homesteads and other land use types were included in these lands. Due to the above reasons, new lands had to be identified for resettlements and for cultivation purposes. In addition, new townships also emerged to serve the people in this area.

During the construction of the dam project, the villagers had the opportunity to work as unskilled labourers in the dam construction site. Both large and small scale fresh water 
fishing activities, various farming activities had emerged everywhere providing new career opportunities for the villagers. In addition, new cultural trends such as 'Eco Tourism' has emerged in the region based on the scenic beauty and the natural environment of the reservoir area.

It is clear that eastern part of the area of the reservoir is a part of VRR (Victoria, Randenigala, Rantambe) National Wildlife Sanctuary. Therefore, various animals, especially birds are very common in the area. Locals and foreigners gather in these areas for bird watching and for boating. The establishment of luxurious star range hotels has also increased the value and the significance of the region.

This has changed the routine activities and culture of the traditional society. At present, the villagers are gaining the benefit of tourism by selling various handmade items, guiding the tourists, providing boating and fishing facilities.

\section{CONCLUSIONS}

The construction of Victoria reservoir has inundated 1925 hectares of land, including paddy and coconut lands. In addition, there is a considerable land use change in the study area from 1954 to 2003 as a result of the development activities that had taken place with time.

Victoria dam project has affected the road network and a total of nearly $29 \mathrm{~km}$ of roads has been inundated. The affected roads include major and minor roads and footpaths. With these changes in land use, road infrastructure and the evacuation of people in the area which was inundated considerable changes in the cultural landscape have occurred. The cultivation patterns, human settlements and natural landscape including flora and fauna of the region have formed new trends to the culture and the landscape than before.

Hydrological network is the most important as it is the main reason for the changes in the cultural landscape of the study area. The major change in terms of hydrological network during the study period from 1954 to 2003 is the conversion of uplands to water as a result of the reservoir.

Therefore, this analysis confirms that there is a significant change in the cultural landscape of the study area during the study period and the Victoria dam project is largely responsible for these changes.

\section{REFERENCES}

Fowler, P.J. (2003). World Heritage:World Heritage Cultural Landscapes 1992-2002. UNESCO World Heritage Centre, France.

Madduma Bandara, C. M. (1982). Report of a Survey of the People and Private Property Affected by the Victoria Reservoir Project, Vol.-1. Victoria Project, Kandy.

Mahaweli. (1986). Projects and Programme, Ministry of Mahaweli Development, Colombo, Sri Lanka. 
Somasekaram, T. (1997). Arjuna's atlas of Sri Lanka, Arjuna Consulting Co. Ltd., Dehiwela, Sri Lanka.

Survey Department of Sri Lanka. (1954). 1: 63,360 scale topographic map of Survey Department of Sri Lanka.

Survey Department of Sri Lanka. (2003). 1: 50000 scale topographic map of Survey Department of Sri Lanka.

World Commission on Dams. (2001). Dams and Development - A New Framework for Decision Making. [ access 30 September, 2010 ]. Available from internet : http:// www.dams.org/publications/publication3.htm. 